Postprint version published in Nature Climate Change $14^{\text {th }}$ April 2013 doi:10.1038/nclimate1807

http://www.nature.com/nclimate/journal/vaop/ncurrent/full/nclimate1807.html

Paper accepted for publication $18^{\text {th }}$ December 2012.

\title{
Deliberating Stratospheric Aerosols for Climate Geoengineering and the SPICE Project
}

\author{
NICK PIDGEON ${ }^{1}$, KAREN PARKHILL ${ }^{1}$, ADAM CORNER ${ }^{1}$ and NAOMI \\ VAUGHAN ${ }^{2}$
}

\footnotetext{
${ }^{1}$ Understanding Risk Group and Tyndall Centre for Climate Change Research, School of Psychology, Cardiff University, Cardiff CF10 3AT, UK

${ }^{2}$ Tyndall Centre for Climate Change Research, School of Environmental Sciences, University of East Anglia, Norwich, NR4 7TJ, UK
}

Corresponding author: PidgeonN@cardiff.ac.uk

Intro Para [118]

Rising concerns about the narrowing window for averting dangerous climate change have prompted calls for research into geoengineering, alongside dialogue with the public regarding this as a possible response. We report results of the first public engagement study to explore the ethics and acceptability of stratospheric aerosol technology and a proposed field trial (the SPICE 'pipe and balloon' test-bed) of components for an aerosol deployment mechanism. While almost all of our participants were willing to allow the field trial to proceed very few were comfortable with using stratospheric aerosols. A secondary aim of the paper is to describe how these findings 


\section{were used in a responsible innovation process for the SPICE project initiated by the UK's Research Councils.}

The Royal Society defines geoengineering as the deliberate large-scale manipulation of the planetary environment to counteract anthropogenic climate change ${ }^{(1)}$, with two distinct approaches identified: carbon dioxide removal (CDR) techniques, which extract $\mathrm{CO}_{2}$ directly from the atmosphere, and solar radiation management (SRM) techniques, which aim to reflect a small percentage of the sun's light and heat back into space. CDR techniques include proposals to sequester carbon dioxide from the atmosphere using large chemical processing, or the industrial-scale production and burial of biochar. Suggested SRM approaches include the enhancement of marine cloud albedo or the injection of reflective aerosols into the stratosphere.

SRM is already proving controversial. There are uncertainties over its effects on ecosystems and global weather patterns ${ }^{(1)}$, and it does not address the fundamental causes of climate change or secondary impacts such as rising ocean acidification ${ }^{(2)}$. SRM also raises trans-boundary issues, as unilateral intervention could impact other countries or populations, and once started SRM would require long-term commitment by global society, since termination whilst atmospheric $\mathrm{CO}_{2}$ concentrations remained elevated would lead to a rapid rise in temperatures ${ }^{(3)}$. This suggests the need for an early international governance regime for $\mathrm{SRM}^{(1)(4)}$, something which itself might prove challenging given recent difficulties with conventional climate negotiations. Such concerns transcend traditional questions of environmental risk assessment, raising fundamental questions about the public value of science and the acceptability to society of the options for responding to climate change. Accordingly, the Oxford Principles ${ }^{(5)}$ for the governance of geoengineering research, as well as reports by the UK Royal Society ${ }^{(1)}$ and the US Government Accountability Office, ${ }^{(6)}$ all recommend public engagement for exploring the acceptability of geoengineering.

Public engagement is a well-established area of social sciences research methodology ${ }^{(7)(8)}$. Fiorino $^{(9)}$ describes 3 generic aims of this: normative (engagement is a valuable activity in and of itself in a democratic society), instrumental (decisions are thereby rendered more transparent, trustworthy, and more likely to be acceptable to people), and substantive (generating new information about risks, values and ethical concerns for informing decisions). With emerging technologies public engagement is often described as 
'upstream', and involves various public(s) deliberating a scientific or technological issue throughout the early processes of scientific research, development and issue framing, before significant commercial realization has taken place ${ }^{(10)}$. Salient questions for upstream engagement include: What is a development for? What is the need? Who owns it? Who will be responsible if things go wrong? This approach has been successfully used for biotechnology $y^{(11)}$, nanotechnologies ${ }^{(12)(13)}$ and synthetic biology ${ }^{(14)}$. Stirling ${ }^{(15)}$ elaborates one particularly important substantive objective of upstream public participation: to avoid premature closure of issue framing and decision options, through efforts to open up the process of problem definition to as many different perspectives as possible. Although extended expert peer review can help with this to a certain extent, the value of public engagement here is to establish whether there are facets of the issue, or value-based concerns, deemed unimportant or trivial by scientists and other expert commentators but which are likely to prove significant for laypeople. And while expert peer analysis might be able to specify the range of potential novel risks, ultimately only society can adjudicate on their acceptability $^{(16)}$. Accordingly, some large multi-stage engagement processes involve quite elaborate combinations of both extended expert review and lay public deliberation ${ }^{(17)}$.

The very first public dialogue to be conducted for geoengineering was the Natural Environment Research Council's 'Experiment Earth?', a series of structured public discussion groups held in $2010^{(18)}$. Around 30 people in each of several locations in Britain were invited to debate the moral, ethical and societal implications of funding research into geoengineering. Through a combination of small group discussions led by professional facilitators, and presentations given by scientists, ethicists and civil society commentators, participants deliberated about nine geoengineering technologies. The controllability and reversibility of such technologies, as well as the adequacy of regulatory arrangements, were identified as key criteria on which future research should be judged.

One criticism often leveled at public engagement exercises is that the findings may have little impact in policy terms - in effect they routinely have "nowhere to go, ${ }^{(19)}$. With the current dialogue, however, the study was commissioned to be used within a responsible innovation process specified by the UK Research Councils (RCUK). Responsible innovation aims to embed an explicit evaluation of the wider worth, impacts, unanticipated risks, and ethical implications into the R\&D process for a new technology ${ }^{(20)(21)(22)}$. 
The current study forms part of the Integrated Assessment of Geoengineering Proposals (IAGP) project, which is developing a comprehensive assessment framework for evaluating geoengineering options. In parallel to IAGP, a second program of research was commissioned in 2010 by RCUK, the Stratospheric Particle Injection for Climate Engineering (SPICE) project. SPICE focuses on the means, efficacy, impacts and modes of delivery of the stratospheric aerosol approach to SRM. The SPICE work-package investigating modes of delivery involves the exploration of the engineering challenges of delivering aerosols continuously through a $20 \mathrm{~km}$ pipe held in place by a giant helium-filled balloon primarily by means of desk-based and modeling work. However, the SPICE researchers also proposed to conduct a field-trial of a scaled-down $1 \mathrm{~km}$ 'pipe and balloon' system (hereafter the 'test-bed'), involving the pumping of fresh water, primarily to observe the movements of the pipe and balloon under various wind conditions (Figure 1).

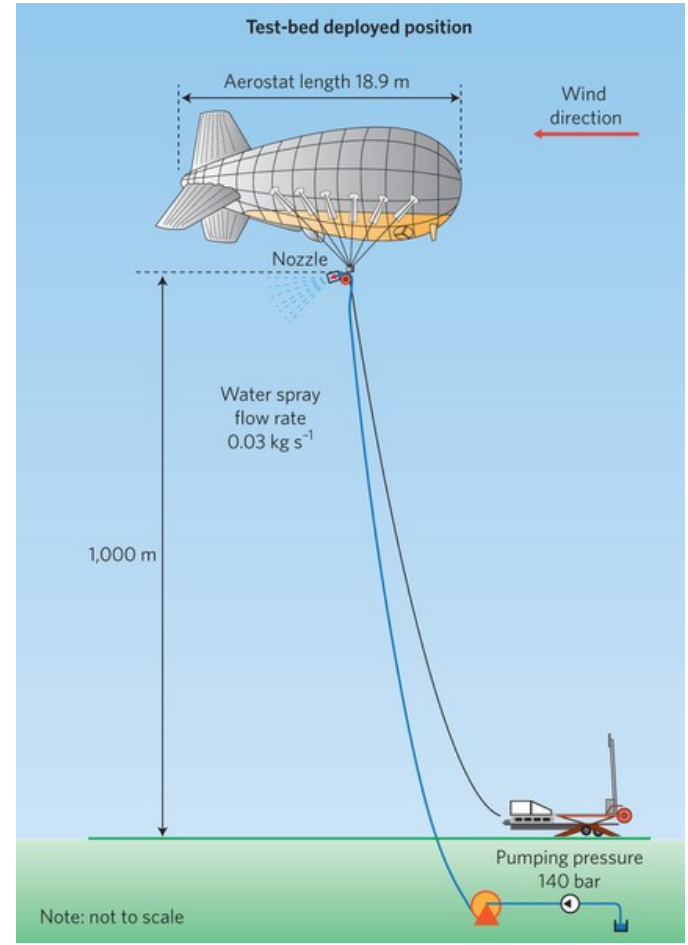

Figure 1 Schematic of the SPICE test-bed proposal (Figure courtesy of Kirsty Kuo, Cambridge University Engineering Department).

The SPICE test-bed takes SRM research beyond the relatively uncontroversial territory of laboratory modeling and simulation into the realm of real-world testing of SRM deployment, and quickly attracted fierce criticism from some Non-Governmental Organisations. It is worth reflecting briefly on why proposals for such a small engineering 
test, effectively posing no major risk to humans or the environment, attracted such levels of opprobrium. As the Royal Society's 1992 risk report ${ }^{(16)}$ makes clear, many so-called 'crises of technology' are often less about the technology per se, or the absolute level of risk involved, which in some cases might be quite trivial. Rather, people's responses involve a range of legitimate concerns and value-based questions which go beyond formal measurement of risk. Reflecting this, in an open letter to the then Minister responsible for UK climate policy, a group of international civil society organisations argued that SPICE would be a dangerous distraction from the need for deep emissions cuts, sending a signal that the $\mathrm{UK}$ is "not negotiating in good faith to reduce emissions, but is instead preparing to proceed down an alternative, very high-risk technological path"(23). For some, then, the SPICE fieldtrial represents a step too far, down a very slippery slope towards a future where humannature-society relationships are altered irrevocably. One might dismiss such objections simply on the grounds that people have unintentionally shaped the natural world for millennia, and that, philosophically speaking, geoengineering is no different in this regard. However, intentional manipulation of the climate is different in legal and ethical terms. ${ }^{(24)(25)}$ Work on public opposition to biotechnology has also demonstrated how people's unease about the 'unnaturalness' of the technology was bound up with a wider storyline about not 'pushing nature beyond its limits', and concerns over long-term unintended consequences and the degree to which scientists' visions of increased technological control over nature and human society were ethically acceptable ${ }^{(11)}$. It is not difficult to see why SRM has characteristics which evoke similar cultural narratives, something which may also help to explain its sensitivity amongst many climate scientists, regulators and academic commentators.

In keeping with the responsible innovation approach RCUK held back funding for the SPICE test-bed component until additional materials and evidence could be evaluated through a "Stagegate" process ${ }^{(26)}$. Specifically, the SPICE project team were asked to satisfy five evaluation criteria, listed in Box 1. The current public engagement study was commissioned to address one half of criterion 5: specifically, the response of informed laypeople to the test-bed, after giving due consideration to stratospheric aerosols and geoengineering more broadly. The present study was not designed to address the equally important question of stakeholder views (the second element of Criterion 5 in Box 1): i.e. of professional and interest groups including regulators, scientists, businesses, environmental groups etc. Equally, and as Box 1 makes clear, public deliberation can only ever provide a 
part of the information needed to decide whether a potentially controversial piece of scientific research should proceed or not.

Survey research has shown that levels of public familiarity with geoengineering are extremely low ${ }^{(27)}$. As it is very difficult for people to debate issues with which they are unfamiliar, we developed a 1.5-day generic methodology successfully used with nanotechnologies $^{(12)}$ in the form of an invited micro-deliberation ${ }^{(28)}$. A cross-section of the general public were recruited to take part in a structured series of learning and deliberative phases (see Methods Section). Throughout we were acutely aware of the importance of the balance between providing enough information to facilitate informed debate, while also avoiding unduly influencing participants through over-framing the issues for them. ${ }^{(10)}$ While few participants had heard of geoengineering before, as found with other topics ${ }^{(29)(30)}$, once given basic information they were able to debate and critically interrogate many of the technical and social issues involved, as well as generate a range of questions of their own. Many of them were also surprised to learn that the views of the public were being sought in this way.

\section{Findings: Geoengineering and Solar Radiation Management}

Previous studies ${ }^{(18)(31)}$ have suggested that people may prefer CDR over SRM. The present findings corroborate this and help to explain why. Fundamentally, participants felt that SRM would only provide a stop-gap response to climate change. As one put it, "because you're not actually changing the conditions that created it. All you're doing is controlling the temperature". Perceived 'naturalness' was also a powerful stimulus for engendering concerns about environmental consequences of geoengineering, with SRM perceived as interfering with natural processes: "they're very unnatural, and I think that, in a way, worries me because it's...probably doing something that we shouldn't'. Stratospheric aerosols in particular were also depicted by some as contributing to a disassociation of humankind from the physical world, with uncertainties and global risks deemed likelier as a result. Through discussing stratospheric aerosols and cloud brightening, participants also questioned how SRM would be managed, controlled, reversed (if necessary), or whether its efficacy could ever be judged given the complex, interrelated systems involved. 
Echoing academic commentary ${ }^{(24)(25)(32)}$ ethics and governance issues were seen as particularly problematic for stratospheric aerosols: e.g. if the negative impacts affected countries which had not themselves deployed the technologies. Many participants felt that there was an imperative to develop some form of international governance structure capable of seeking consensus for developing and deploying the technology, as well as determining codes of conduct for their responsible use. However, the extent to which such a consensus on aerosol deployment could ever be achieved was also questioned: "It's a concern because when they've had these climate change seminars [e.g. Kyoto] and groups, nobody ever agrees and what guarantee would we have that everybody would actually agree over something like this?" Such views did not rule out conducting research on aerosols or solar radiation management, since for some there was reassurance in scientists investigating all potential avenues, ensuring there are spaces for innovation, ingenuity, and novel developments to address climate change.

\section{Findings: The SPICE Test-Bed}

Participants' views of the general idea of stratospheric aerosols discussed on Day 1, and the specific SPICE test-bed proposals introduced on Day 2, inhabited very different discursive spaces. That is to say, the set of perceptions, associations and interpretations (often negative) people held of stratospheric aerosols did not automatically inhibit support for the test-bed when framed as a strictly-limited research opportunity. However, these sets of discourses were not wholly separate, with linkages occurring when initial questions regarding the test-bed evolved into queries and concerns about the implications for full-scale deployment. To illustrate this point we discuss in more detail the questions generated by participants at the beginning of Day 2, under four categories: safety and impacts; methodology and justification; knowledge limitations; governance and communication.

Safety and Unintended Impacts An unequivocal concern was that the test-bed should be safe. Questions centered on how safety would be ensured (would the team conduct a risk assessment?), how danger would be avoided (e.g. for aircraft), and what were the implications if something did go wrong? This included safety for humans - those operating the test-bed, in close proximity to the test, or who might otherwise be impacted - and wider environment/ecosystems. Whilst some of these concerns might seem straightforward to address, these data demonstrate how associations with other risk issues, personal memories, 
and experiences are likely to form the basis of people's initial 'mental models' when they encounter geoengineering for the very first time ${ }^{(31)}$. For example, some participants wished to know if the balloon gas would be flammable, making reference to the Hindenburg disaster in 1937. Other participants made associations between the test-bed (and full-scale deployment) and accidents such as Chernobyl. Such remarks should not be interpreted literally, but do reflect important ambivalences and cautions that many people hold regarding possible unintended consequences of scientific progress ${ }^{(33)}$, albeit expressed indirectly, through metaphors and analogies highlighting past (and potential future) socio-technical failures $^{(34)(35)}$.

Research Methodology Given that on Day 1 our participants had already voiced significant reservations regarding stratospheric aerosols, they engaged critically with all aspects of the methods and research process underpinning the test-bed on Day 2. Importantly, questions were not restricted to logistical inquires into where or how the test-bed would operate: participants were also deeply interested in why the researchers and funders had opted to pursue these lines of enquiry. Most fundamentally, for some participants, an apparent lack of such justification threatened to undermine the worth of the test-bed entirely. Whilst many saw value in completing the engineering test at this stage, others questioned why this was occurring at all, and before other more crucial questions had been answered. As one participant put it, "I think you could well be wasting a lot of money. I don't think that this will be cheap and you're looking at a delivery system....you don't know whether you're actually going to use it because you don't know the effects of the actual technique. I think you've got to see whether the technique works before you can deliver it or not". A final justification sought by participants was whether there was any real need to pursue stratospheric aerosols at all, over and above efforts at carbon reduction (both CDR and conventional mitigation).

Knowledge Limitations. A very subtle line of questioning addressed the limitations to knowledge generated through the pipe and balloon trial, with the set of questions generated shown in Box 2. Precisely what knowledge could the test-bed provide to assist with future research (and possibly full-scale deployment)? Accepting that the $1 \mathrm{~km}$ test-bed was concerned with providing information regarding practical or engineering elements related to the mechanics of the pump, tethering system, and the balloon, did not preclude critical questions regarding the ability to upscale results, particularly given the differences between 
the conditions of the test-bed and any full-scale deployment. We may never know the true impacts of solar radiation management without deployment ${ }^{(36)}$ and the comments of our participants reflected similar sentiments, regarding up-scaling to $20 \mathrm{~km}$ (different heights, temperatures, location etc.) and whether the approach to radiation management itself would work as proposed. For some, until they became aware of the significant engineering challenges in pumping a fluid up a pipe connected to a balloon, there seemed to be an air of frustration that the test-bed would be so far removed from the 'end point' conditions of deployment. Even with rigorous and systematic multi-staged research we may never know enough and even then, in the event that something went wrong, how could we trace the cause?

Governance and Communication. In common with Experiment Earth ${ }^{(18)}$, and findings from other technologies $^{(11)(12)(33)}$, participants in all of the workshops were interested in how stratospheric aerosols at full-scale deployment would be governed, regulated and communicated (Box 3). It was important that there should be some form of international governance structure for SRM, and through discussions about the SPICE research and testbed it became clear that governance structures should be, whilst not necessarily already in place, at least being worked on. This was to ensure that global debate about what would ultimately be a global initiative was in place - otherwise even pursuing research into it would be fruitless. Some participants felt that good communication structures would help to ensure the research would be seen as legitimate rather than fringe science, or scient ists and the UK "going rogue". Communicating - being transparent and open about research such as SPICE within the international and national arena - was not just seen as necessary, but obligatory. A variety of actors were held responsible for ensuring such communication takes place, including politicians and the researchers themselves. Simply relying on traditional means of communicating science (e.g. international conferences and science journals) was not seen as satisfactory by our participants, with dissemination needed to national publics (to maintain/build trust) and the local communities close to the test-bed site.

\section{Discussion.}

Our findings suggest that the development of stratospheric aerosol technologies holds the potential for significant public concern and controversy. Concerns centered upon the inability to address the fundamental problem of rising greenhouse gas emissions, possible 
unintended consequences, and the perceived 'unnaturalness' of the technique. Perhaps more importantly, aerosols were also seen to raise significant problems of international governance and control, underlining the importance of current efforts to develop research governance structures $^{(4)(5)}$. Our respondents were nonetheless reluctant to rule out the SPICE test-bed as a limited scientific and engineering test. In all of our groups we observed a marked alteration in discourse from the end of Day 1, where views on aerosols were broadly negative, to a more nuanced and ambivalent set of frames when debating SPICE during Day 2. However, participants were also clearly uncomfortable with what might happen next, were the test-bed to be given the go-ahead. How could the knowledge gained be usefully employed? What societal controls might ultimately be needed on stratospheric aerosols? Who would take responsibility to oversee this process? It is these epistemological, social and institutional ambivalences, issues intertwined with the strictly technical and science questions, which are the key outcomes from our study, and which pose the greatest challenges for future stratospheric aerosol research and SRM governance efforts.

Our report from the workshops ${ }^{(37)}$ was delivered to the RCUK Stagegate panel convened in June 2011 to consider the SPICE project. Our conclusions included:

- Almost all of our participants were willing to entertain the notion that the test-bed as an engineering test - a research opportunity - should be pursued. That being said, the research could only proceed (a) if the test-bed was safe for local inhabitants and the environment, and (b) SPICE were fully transparent and open about this. Information relating to the safety and impacts of the test-bed should be made fully accessible for locally affected people, who should also be treated as active participants in that communication process.

- Equally, very few in our study were fully comfortable with the notion of stratospheric aerosols, with their discourses about this and the test-bed often operating simultaneously within several frames. Accordingly, acceptance of the test-bed should not be misconstrued as unconditional acceptance of, or support for, either stratospheric aerosols or geoengineering more generally but rather a highly 'conditional' or 'reluctant acceptance ${ }^{(38)}$ of pursuing the test-bed as part of a carefully developed research strategy. The ambivalences of our participants were indicative of 
their desire that strategic research decisions (e.g. regarding the outcomes and followon from SPICE) did not lose sight of the end goal of scaling-up to potential full deployment.

- Whilst developing new scientific and technical knowledge was important for our participants, they felt that funding decisions for both the test-bed and any future research stemming from it should be based as much on issues of governance and ethics, as on science and engineering criteria. A related issue for our participants was that RCUK should make transparent their strategy for funding geoengineering research and SPICE, and how this would fit within their strategy for supporting research on responses to climate change.

- A key concern for participants was that international governance and regulatory structures be under development now to help shape geoengineering research such as the test-bed, SPICE and future developments arising.

The test-bed proposal was deemed to meet the public engagement criterion of the Stagegate, although not all other criteria were fulfilled at that point in time ${ }^{(26)}$. In particular, the SPICE team were asked by the panel to undertake engagement with involved stakeholders (the second element of Criterion 5, Box 1). The value of the public engagement for the Stagegate process was not so much in its (limited) endorsement of the SPICE test-bed ambitions, but as a means of highlighting critical issues of concern to our participants falling under Criteria 1, 3 and 4. Although the safety aspects of the test-bed (Criterion 1) had already been addressed by the SPICE team through a risk assessment prepared for the Stagegate, they were requested by the panel to reflect on our findings in developing a communication plan for communities in the vicinity of the test-bed (Criterion 3). As our participants had also raised the wider 'what next' question, SPICE were additionally asked to keep under review, as a 'living document', the risks, ethics and social aspects of SPICE and SRM more generally (Criterion 4): in effect to undertake reflexive appraisal as the project moved forward from that point on. Our findings also hold significant implications for research funders and scientists working on geoengineering in the future, highlighting some of the conditions (international governance, thorough consideration of the implications of scaling-up, an ethical as well as technical review) that lay publics might wish to place on moves toward funding larger-scale SRM and aerosol research. As a postscript to the present study, the SPICE test- 
bed was eventually cancelled in June of 2012, primarily because of difficulties surrounding a patent application for the pipe technology. Although intellectual property was not an issue that emerged to any great extent in our groups, concerns about the conditions under which geoengineering might become commercialised in the future did. Here, a number of our participants spontaneously expressed suspicion of the involvement of commercial interests, arguing for a mechanism for societal oversight given that this issue held such major global and environmental consequences for us all.

The study serves as one model for successfully embedding public dialogue within a responsible innovation process. But it represents only the starting point in understanding how global publics, in all their variety and complexity, will respond to geoengineering proposals as they become more prominent in the media and policy spheres. The study engaged a crosssection of participants from a single Western European nation and a particular cultural context. Although European social researchers have successfully experimented for well over 20 years using this invited micro-dialogue format the approach has recently attracted considerable methodological and philosophical discussion. Commentators have argued that such methodologies of engagement, first developed extensively in the context of Danish civic culture and the 'consensus conference' approach, may not always transfer successfully to countries with very different cultures of citizen participation ${ }^{(39)}$. For example, Dryzek and Tucker argue that the advocacy politics present in countries such as the USA can seriously bias the outcomes of public engagement ${ }^{(40)}$. However, recent evidence from citizen engagements with nanotechnologies ${ }^{(12)(41)(42)}$ suggests that many of the conditions which are held to bias outcomes are absent when an emerging technology is sufficiently 'upstream' (since by definition strong advocacy positions have yet to emerge) or can be overcome with careful process design. Equally, recruiting a cross-section of the public with little prior experience of the issue, to debate an issue framed in the terms set by a sponsoring institution, risks merely reproducing those institutionally defined framings ${ }^{(43)}-$ or, in Stirling's ${ }^{(15)}$ terms, of prematurely 'closing down' the range of potential options and issues under consideration. Invited dialogue processes also construct 'the public' in a very particular way. ${ }^{(44,45)}$ By giving voice to the constituency who do not typically express their views on science and technology (in effect using a 'lay jury' model) this excludes more vocal proponents/opponents on the grounds that they do not represent the 'authentic' voice of society. In the present case deliberating with the more vocal was due to be met, after the Stagegate review, through the SPICE team themselves consulting relevant stakeholder groups. Our own view is that 
societies are composed of multiple publics, with differing values, levels of interest in an issue, and concerns, and as a result we will need varied means for engaging these different constituencies. The challenge now for the geoengineering research community is to find further innovative, culturally sensitive ways to engage a much wider set of publics - those with particularly strong views on climate change or geoengineering, or those in other countries and regions, especially developing ones, where climate change or geoengineering impacts are likely to be extreme. Such public dialogue will be an essential component in the global debate about geoengineering research and its governance that now needs to be conducted.

[Main Text Words 4166]

\section{Methods}

After extensive piloting a deliberative workshop format was developed which facilitated people from different social positions taking part. Workshops were completed in three British cities each with 8-12 participants (total $n=32$ ). Locations were selected to reflect a socioeconomically diverse national capital (Cardiff), semi-rural area and city (Norwich), and a former industrial city (Nottingham). In order to elicit a diverse range of viewpoints sampling was designed to capture a broad demographic cross-section of the population at each location. The overall sample (see Supporting Table 1) reflected gender, age, socioeconomic grouping, and educational level, as well as the ethnicity mix present in each specific location. Recruitment was 'topic blind', with geoengineering not mentioned during the recruitment: participants were approached in a public place by a representative of a professional recruitment agency to take part in discussions related to 'societal responses to climate change'.

Each workshop was facilitated by the research team, and lasted 1.5 days with a 'homework' task given in between (Supporting Appendix 1 shows the overall structure of each workshop). Day 1 began with facilitated discussion about climate change, followed by a World Café ${ }^{(46)}$ style discussion about potential societal responses to climate change (mitigation, adaptation and geoengineering), and then introduction to 4 geoengineering approaches by a geoengineering expert (NV): biochar, air capture, cloud whitening and 
stratospheric aerosols (for materials used to illustrate these see Supporting Appendix 2) and a further World Café including social and ethical prompts on SRM and CDR. These 4 examples were selected to give a snapshot of the range of most plausible geoengineering approaches and were repeatedly described as being just that, and not an exhaustive list. Following advice from the IAGP independent academic advisory panel, examples were given of research currently taking place, including the full-scale $20 \mathrm{~km}$ pipe proposal for SRM, but without mentioning the SPICE project explicitly at that point. Day 2 began with discussion of the homework task (to describe to a friend or relative what people had learned from day one), a brief overview of the SPICE test-bed, the RCUK Stagegate process, and the reason why the workshops were being held. Participants then developed together a series of questions that they wished to see answered about SPICE. We viewed this question generation as the most important activity of the whole workshop, in that it elicited, in all three workshops, a very wide range of responses to the proposed field-trial, ranging from the very practical to the philosophical. This was followed by the opportunity to question a member of the SPICE research team from the Cambridge Engineering Department about any of these, ending with final parallel small group discussions about SPICE and a wrap-up plenary. Workshops were held in public spaces and participants were given a small financial honorarium. All sessions were audio- and video- recorded, and full verbatim transcriptions made of all conversations which were independently professionally verified and anonymised. Systematic and rigorous qualitative data analysis of the transcripts was conducted ${ }^{(47)}$ with themes and interpretations discussed extensively by the research group.

Considerable effort was expended to ensure all materials were accurate, including being reviewed by experts in geoengineering and climate science. In addition, social scientists and third sector representatives with expertise in governance, regulation and ethics also reviewed the materials. Careful attention was paid to the framing of materials. Whilst climate change was emphasised as requiring urgent action, geoengineering as an 'emergency' response or 'emergency stop button' framings were not introduced by the research team. Other framings avoided throughout the workshops (as a result of our analysis of issues arising with the earlier 'Experiment Earth' methodology) were 'naturalness' or 'mimicking natural processes', and 'carbon removal as dealing with the cause of climate change'. If such responses/issues emerged spontaneously from the participants, as they at times did, these were explored further, but the researchers themselves avoided introducing them. Estimates of costs of different approaches were also not presented: we stressed throughout that due to the 
uncertainties surrounding costs and unintended impacts, nobody could currently answer this question with any confidence. The key orienting framing used throughout was that

geoengineering may be one possible response to climate change as a risk issue ${ }^{(48)}$, rather than a debate about whether global warming was 'real' or not. Of course, there is no entirely neutral framing of such a controversial issue, and one cannot entirely rule out unintended framings entering the debate through either particular materials presented, or prompting from the facilitator team. However, throughout we were very sensitive to participants' own constructions which we explored exhaustively through the extensive use of prompts such as "what makes you say that?", "could you say a little of why you are interested in knowing that?" As such, our public(s) were active participants in the workshops and deliberative processes, capable of and encouraged to engage critically with all of the information and also to develop their own framings in an open and reflexive way. For a fuller discussion of methods see Parkhill and Pidgeon ${ }^{(37)}$.

[Methods Words 824]

\section{Acknowledgements}

The research was supported by the Engineering and Physical Sciences Council and Natural Environment Research Council through the Integrated Assessment of Geoengineering Proposals project grant (EP/I014721/1). Additional support was provided by the US National Science Foundation through the Center for Nanotechnology in Society at the University of California at Santa Barbara (cooperative agreement SES 0938099). We wish to thank Merryn Thomas for assistance with the workshops, Kirsty Kuo, Hugh Hunt and Matthew Watson of the SPICE project, and the IAGP advisory panel for comments on materials. Any opinions, findings, and conclusions or recommendations expressed in this paper are those of the authors and do not necessarily reflect the views of the EPSRC, NERC or NSF.

\section{Author Contributions}

The study was conceived by NP and AC. The detailed design and materials were developed by all authors. Data collection was conducted by KP, NP and NV, and the analysis by KP and NP. NP wrote the paper with contributions from all other authors. Correspondence for reprints should be addressed to NP.

\section{Additional Information}


The authors declare no competing financial interests.

\section{Proposed Supplemental Online Information}

Supporting Table 1: Demographic Characteristics of the Participants

Supporting Appendix 1: Workshop Format \& Tasks Overview

Supporting Appendix 2: Slides used to introduce the geoengineering techniques. 


\section{REFERENCES}

1. Royal Society Geoengineering the Climate: Science, Governance and Uncertainty. Science Policy Centre Report 10/09. (The Royal Society, 2009).

\section{A key first review of geoengineering proposals, their possible risks and uncertainties}

2. Vaughan, N.E. \& Lenton, T.M. A review of climate geoengineering proposals. Clim. Chg. 109, 749-790 (2011)

3. Matthews, H.D. \& Caldeira, K. Transient climate-carbon simulations of planetary geoengineering. Proc. Nat. Acad. Sci. 104, 9949-9954 (2007).

4. Solar Radiation Management Governance Initiative. Solar Radiation Management:

The Governance of Research. (The Royal Society, 2011).

5. Rayner, S. et. al. Draft principles for the conduct of geoengineering research (the

'Oxford Principles'). Reproduced in House of Commons Science and Technology

Committee, The Regulation of Geoengineering, Fifth Report of the session 2009-2010, HC221 (The Stationary Office, $18^{\text {th }}$ March 2010).

6. US Government Accountability Office Climate Engineering: Technical Status, Future Directions and Potential Responses, Report GAO 11-71. (GAO, 2011).

7. Renn, O., Webler, T. \& Wiedemann, P. Fairness and Competence in Citizen Participation: Evaluating Models for Environmental Discourse. (Kluwer, 1995).

8. Dietz, T. \& Stern, P. (ed.) Public Participation in Environmental Risk Assessment and Decision-Making. (National Academies Press, Washington 2008).

9. Fiorino, D. Citizen participation and environmental risk: a survey of institutional mechanisms. Sci. Tech. Hum. Values 15(2), 226-243 (1990).

10. Rogers-Hayden, T. \& Pidgeon, N.F. Moving engagement "upstream"?

Nanotechnologies and the Royal Society and Royal Academy of Engineering inquiry. Publ. Und. Sci. 16, 346-364 (2007).

11. Marris, C. Public views on GMOs: deconstructing the myths. EMBO Rpts. 21(7), 545548 (2001).

12. Pidgeon, N.F., Harthorn, B., Bryant, K. \& Rogers-Hayden, T. Deliberating the risks of nanotechnology for energy and health applications in the US and UK. Nature Nano. 4, 9598 (2009).

This US-UK deliberative study with nanotechnologies serves as a model for the invited micro-dialogue methodological approach to geoengineering engagement.

13. Burri, R.V. Coping with uncertainty: assessing nanotechnologies in a citizen panel in Switzerland. Publ. Und. Sci. 18, 498-511 (2009).

14. Bhattachary, D., Calitz, J.P. \& Hunter, A. Synthetic Biology Dialogue. (Final Report For Sciencewise/BBSRC, 2010).

15. Stirling, A. Deliberate futures: precaution and progress in social choice of sustainable technology. Sustain. Devpt. 15, 286-295 (2007).

16. Pidgeon, N.F., Hood, C., Jones, D.K., Turner, B.A \& Gibson, R. Risk perception. in Risk - Analysis, Perception and Management: Report of a Royal Society Study Group, pp 89134, (The Royal Society, 1992)

17. Renn, O. in The Social Amplification of Risk (eds Pidgeon, N.F., Kasperson, R.K. \& Slovic, P.) pp 374-401 (Cambridge University Press, 2003). 
18. NERC. Experiment Earth: Report on a Public Dialogue on Geoengineering. (Natural Environment Research Council, 2010). Available from www.nerc.ac.uk/about/consult/geoengineering-dialogue-final-report.pdf

19. Jasanoff, S. Technologies of humility: citizen participation in governing science. Minerva 41, 223 - 244 (2003).

20. Rip, A., Misa, T.J. \& Schot, J. Managing Technology in Society: The Case of Constructive Technology Assessment (Pinter Press, 1995).

21. Guston, D.H. \& Sarewitz, D. Real-time technology assessment. Technology in Society 24, 93-109 (2002).

\section{Philosophical discussion of the framework and purposes of responsible innovation approaches.}

22. Owen, R. \& Goldberg, N. Responsible innovation: A pilot study with the U.K. Engineering and Physical Sciences Research Council. Risk Anal. 30, 1699-1707 (2010). 23. http://www.handsoffmotherearth.org/hose-experiment/spice-opposition-letter/ 24. Corner, A. \& Pidgeon. N.F. Geoengineering the climate: the social and ethical implications. Environment: Sci. and Policy. for Sustain. Devpt. 52(1), 24-37 (2010).

\section{Summaries some of the ethical dimensions to geoengineering proposals and elaborates the case for early (upstream) public engagement.}

25. Gardiner, S.M. Some early ethics of geoengineering the climate: a commentary on the values of the Royal Society report. Env. Values 20, 163-188 (2011).

26. Macnaghten, P. \& Owen, R. Good governance for geoengineering. Nature 479, 293 (2011).

27. Corner, A. Pidgeon, N. \& Parkhill, K. Perceptions of geoengineering: public attitudes, stakeholder perspectives, and the challenge of "upstream" engagement. WIREs Climate Change. doi: 10.1002/wcc.176 (2012).

28. Chilvers, J. Sustainable Participation? Mapping Out and Reflecting upon the Field of Public Dialogue on Science and Technology. (University of East Anglia/Sciencewise, 2010). 29. Irwin, A. \& Wynne, B. Misunderstanding Science? The Public Reconstruction of Science and Technology. Cambridge University Press (1996).

30. Callon, M., Lascoumes, P. \& Barthe, Y. Acting in an Uncertain World: An Essay on Technical Democracy (MIT Press, 2011).

31. Pidgeon, N.F., Corner, A., Parkhill, K., Spence, A., Butler, C., and Poortinga, W. Exploring early public responses to geoengineering. Phil. Trans. Royal Soc. (A) 370, 4176-4196 (2012). 32. Buck, H.J. Geoengineering: remaking climate for profit or humanitarian intervention? Devpt. \& Chng. 43, 253-270 (2010).

33. Macnaghten, P. Researching technoscientific concerns in the making: narrative structures, public responses, and emerging nanotechnologies. Env. \& Plan. A 42, 23-37 (2010).

Reviews the broad lessons learned from social scientists' study of public dialogue around earlier emerging technologies, many of which are likely to apply to SRM proposals

34. Turner, B.A. \& Pidgeon, N.F. Man-made Disasters, $2^{\text {nd }}$ ed. (Butterworth-Heinemann, 1997). 
35. Harremoẽs, P. et al (ed) Late Lessons From Early Warnings: The Precautionary Principle 1869-2000. Copenhagen: European Environment Agency (2001).

36. Hamilton, C. The Ethical Foundations of Climate Engineering. (Australian National University, 2011).

37. Parkhill, K. \& Pidgeon, N.F. Public Engagement on Geoengineering Research: Preliminary Report on the SPICE Deliberative Workshops. Understanding Risk Working Paper 11-01. (Cardiff University, School of Psychology, 2011)

38. Bickerstaff, K., Lorenzoni, I., Pidgeon, N.F., Poortinga, W. \& Simmons, P. Reframing nuclear power in the UK energy debate: nuclear power, climate change mitigation and radioactive waste. Publ. Und. of Sci. 17, 145-169 (2008).

39. Nielsen, A.P., Lassen, J. \& Sandoe, P. Democracy at its best? The consensus conference in a cross-national perspective. J. Agri. and Env. Ethics 20(1), 13-35 (2007).

40. Dryzek, J.S. \& Tucker, A. Deliberative innovation to different effect: consensus conferences in Denmark, France and the United States. Publ. Admin. Rev. 68(5), 864-876 (2008).

41. Philbrick, M. \& Barandarian, J. The National Citizens' Technology Forum: lessons for the future. Sci. \& Pub. Pol. 35(5), 335-347 (2009).

42. Cobb, M.D. Creating informed public opinion: citizen deliberation about nanotechnologies for human enhancements. J. Nanopart. Res. 13, 1533-1548 (2011).

43. Chilvers, J. \& Macnaghten, P. The Future of Science Governance: A Review of Public Concerns, Governance and Institutional Response. (Universities of East Anglia and Durham/Sciencewise, 2011).

44. Wynne, B. Public participation in science and technology: performing and obscuring a political-conceptual category mistake. East Asian Sci., Tech. \& Soc. 1, 99-110 (2007). 45. Lezaun, J. \& Soneryd, L. Consulting citizens: technologies of elicitation and the mobility of publics. Publ. Und. Sci. 16, 279-297 (2007).

46. Brown, J. \& Isaccs, D. The World Café: Shaping our Future through Conversations that Matter. (Berrett-Koehler, 2005).

47. Pidgeon, N.F. \& Henwood, K.L. in Handbook of Data Analysis (eds Hardy, M. \& Bryman, A.), pp 625-648, (Sage, 2004).

48. Pidgeon, N.F. \& Fischhoff, B. (2011) The role of social and decision sciences in communicating uncertain climate risks. Nature. Clim. Chg. 1, 35-41. 


\section{Supporting Table 1: Demographic Characteristics of the Participants}

\begin{tabular}{|lll|}
\hline Gender & Male & 15 \\
& Female & 17 \\
\hline Age & $18-24$ & 6 \\
& $25-34$ & 6 \\
& $35-44$ & 5 \\
& $45-54$ & 4 \\
& $55-64$ & 6 \\
& $65+$ & 5 \\
\hline Educational Level & No formal qualifications & 4 \\
& GCSE or equivalent & 5 \\
& A Level or equivalent & 6 \\
& Vocational & 8 \\
& Degree or equivalent & 5 \\
& Masters/higher or equivalent & 4 \\
\hline Socio-Economic Groupings & A - High managerial, administrative or professional & 4 \\
& B - Intermediate managerial, administrative or professional & 7 \\
& C1-Supervisory, clerical \& junior managerial, administrative or & 6 \\
& professional & \\
& C2 - Skilled manual workers & 6 \\
& D-Semi \& unskilled manual workers & 6 \\
& E-State pensioners, casual or lowest grade workers, & 3 \\
& unemployed with state benefits only & 30 \\
& White British \\
& Black Caribbean & 2 \\
\hline
\end{tabular}




\section{Supporting Appendix 1: Format \& Tasks Overview}

\begin{tabular}{|c|c|}
\hline Main Task & Extra Information \\
\hline \multicolumn{2}{|l|}{ DAY 1} \\
\hline $\begin{array}{l}\text { Introductory Presentation, } \\
\text { Climate Change thought listing task } \\
\text { \& feedback }\end{array}$ & $\begin{array}{l}\text { Thought-listing: "Please list what comes to mind when you hear the term 'climate } \\
\text { change"". } \\
\text { Participant engagement/disengagement and belief/disbelief in climate change were able } \\
\text { to be probed here. }\end{array}$ \\
\hline CC overview presentation & A crash course in climate change, potential effects \& scientific uncertainty. \\
\hline \multicolumn{2}{|l|}{$\begin{array}{l}\text { Group discussions } \\
\text { - Climate Change }\end{array}$} \\
\hline $\begin{array}{l}\text { World Café } 1-\text { Societal responses } \\
\text { to climate change }\end{array}$ & $\begin{array}{l}\text { Split into two small groups, each group discuss each topic in turn: } \\
\text { 1: reduction (mitigation) } \\
\text { Materials provided: } \mathrm{CO}_{2} \text { reduction target, Map of } \mathrm{CO}_{2} \text { emissions per capita } \\
\text { (Bangladesh, China, UK, USA), Foresight Scenarios. } \\
\text { 2: adaptation } \\
\text { Materials provided: Two case studies of adaptation (Flooding in London \& } \\
\text { Coastal Erosion) } \\
\text { 3: climate control (geoengineering) } \\
\text { Materials provided: Very broad intro to geoengineering and two } \\
\text { approaches \& comparison of what CR/RA can and cannot do. } \\
\text { - Introduce material - } 5 \text { mins to review } \\
\text { - A facilitator joins table but only enters discussion if needs guidance/stimulation } \\
\text { - Encourage to record (via sticky notes) pros \& cons for each, \& comparisons }\end{array}$ \\
\hline $\begin{array}{l}4 \text { Techniques of Geoengineering } \\
\text { presentation (using Appendix A } \\
\text { slides) and Q\&A by expert (NV) }\end{array}$ & Participants reasons for asking questions probed before expert (NV) answered \\
\hline $\begin{array}{l}\text { World Café } 2 \text { - Carbon Removal } \\
\text { (Biochar \& Air Capture) \& } \\
\text { Reflective Approaches } \\
\text { (Stratospheric Aerosols \& Cloud } \\
\text { Whitening) }\end{array}$ & $\begin{array}{l}\text { Split into two small groups } \\
\text { Topic 1: CR \& Topic 2: RA ( } 35 \text { mins per topic) } \\
\text { - Materials provided: reminder of } 4 \text { different techniques with advantages \& } \\
\text { disadvantages, \& ethics/governance prompt statements ( } 5 \text { mins review) } \\
\text { - A facilitator joins table but only enters discussion if needs guidance/stimulation } \\
\text { - Aim to record concerns/benefits \& create conditions and rules for approaches, using } \\
\text { governance and ethics prompt sheets }\end{array}$ \\
\hline \multicolumn{2}{|c|}{ Homework: To describe Geoengineering to a friend/family member \& write down their responses. } \\
\hline \multicolumn{2}{|c|}{$\begin{array}{l}\text { DAY } 2 \\
\text { Group feedback on homework including their reflections on family responses and if their own opinions had changed. }\end{array}$} \\
\hline \multicolumn{2}{|c|}{ Group feedback on homework including their reflections on family responses and if their own opinions had changed. } \\
\hline Initial group responses to SPICE & $\begin{array}{l}\text { ALL EXPERTS (including SPICE representative) LEAVE ROOM } \\
\text { - Initial thoughts, discuss \& questions for experts created and recorded on Flipchart. } \\
\text { - Finally probed as to what participants' or friends' responses to a media } \\
\text { article/programme would have been if "uninformed". }\end{array}$ \\
\hline \multicolumn{2}{|c|}{ Experts return and answer questions (primarily directed to representative of SPICE project) } \\
\hline $\begin{array}{l}\text { Two small group discussions - } \\
\text { SPICE }\end{array}$ & $\begin{array}{l}\text { Encourage to reflect upon previous rules/conditions/concerns created on previous day } \\
\& \text { create ones for SPICE } \\
\text { - Probe as to why } \\
-\quad \text { Probe locality } \\
-\quad \text { Probe if notice switch in opinions }\end{array}$ \\
\hline $\begin{array}{l}\text { Small group feedback and whole } \\
\text { group discussion }\end{array}$ & $\begin{array}{l}\text { Representative from each small group reports back from their small group - whole } \\
\text { group discussion stemming from these reports (on SPICE, geoengineering and so forth) }\end{array}$ \\
\hline Anonymous last thoughts SPICE & into a box without telling anyone what is on it. \\
\hline
\end{tabular}




\section{Supporting Appendix 2: Slides used to introduce the geoengineering techniques.}

1

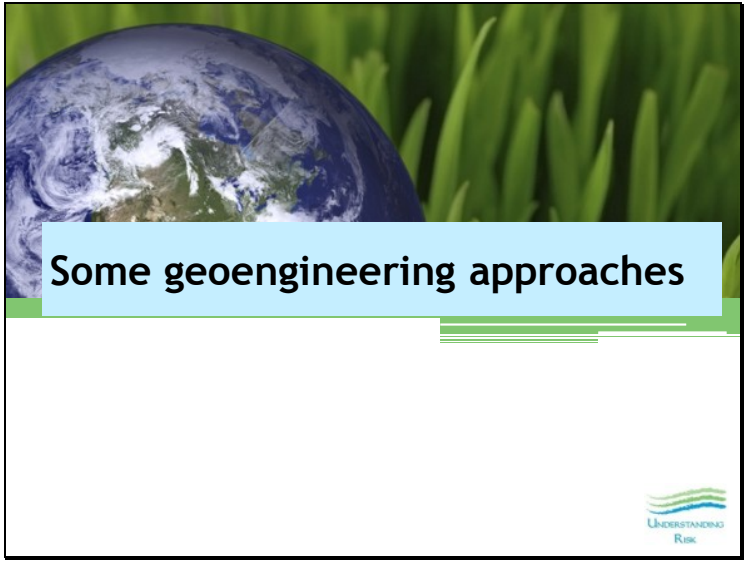

2

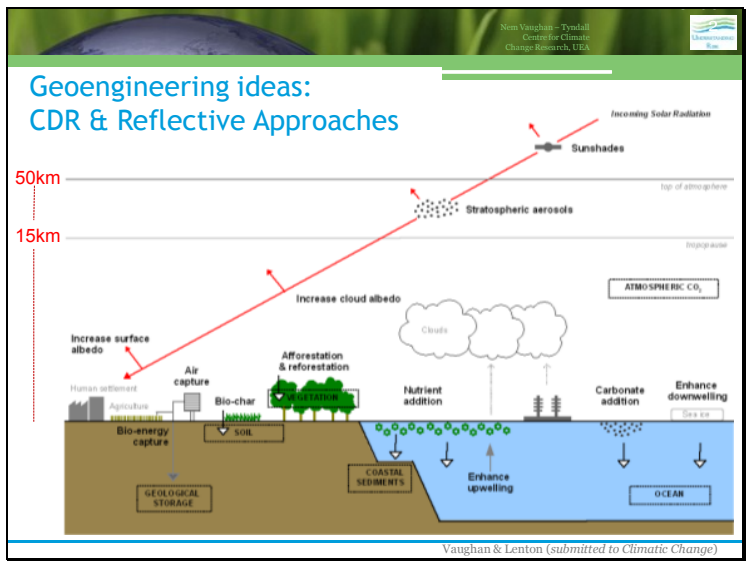

4

1. Biochar
Vegetation removes carbon from the atmosphere during photosynthesis.
When it dies it decomposes releasing its carbon back into the atmosphere
Instead the vegetation is heated and starved of oxygen to lock the carbon
into biochar (charcoal).
The biochar is then buried and it can store away carbon for thousands of
years
uK Biochar Research centre
Headquarters for UKBRC are at
Edinburgh University. The centre
is undertaking disciplinary and
interdisciplinary research on the
role of biochar as a carbon storage
technology.
http://www.biochar.org.uk/

5

Biochar pros \& COns
Pros
- Waste materials can make bio-char; wood, leaves, food waste, straw or manure,
and adding bio-char to soil can improve agricultural productivity
- When making bio-char, biofuels and bio-oils are produced which can be used as
a renewable fuel source
Farmers could make a profit from selling their Biochar, feasible in many places.
Cons
Small scale potential, and timescale for effectiveness (10o years +).
- Will require additional energy consumption for transport, buying and
processing. May disrupt growth, nutrient cycling and viability of the ecosystems involved.
Potential conflicts over land use for agriculture and crops for biofuels




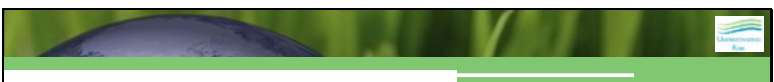

Air capture pros \& cons

Pros

- Very efficient as can remove many more times carbon

dioxide than a tree

Placed anywhere

Capture is very safe and shouldn't have any bad side effects

- Would operate 24 hours a day but could be switched off

easily if something went wrong

Easy to measure the amount of carbon captured

\section{Cons}

They would be slow to reduce global temperatures

The capture devices may be an eyesore and would take up

land space

There will be a limit on places to store $\mathrm{CO}_{2}$ underground

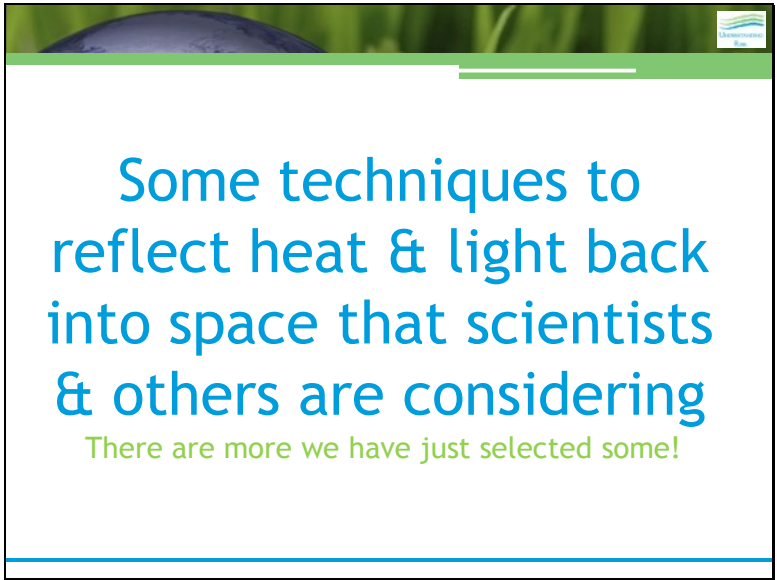

Cloud whitening pros \& cons
Pros
Could start reducing temperatures in a short time period
Easy to turn off if there's a fault
Cons
- It may not be as effective at reducing temperatures as predicted.
- Effects may only last a few days or weeks so it would need to be
carried out repeatedly which would cost money and take time
- It would cause a lot of cooling in a very localised area
- It may have unwanted effects on the weather and sea life
- May reduce or change the patterns of rainfall in other regions
Other impacts of rising carbon emissions still remain e.g.
increasing ocean acidification

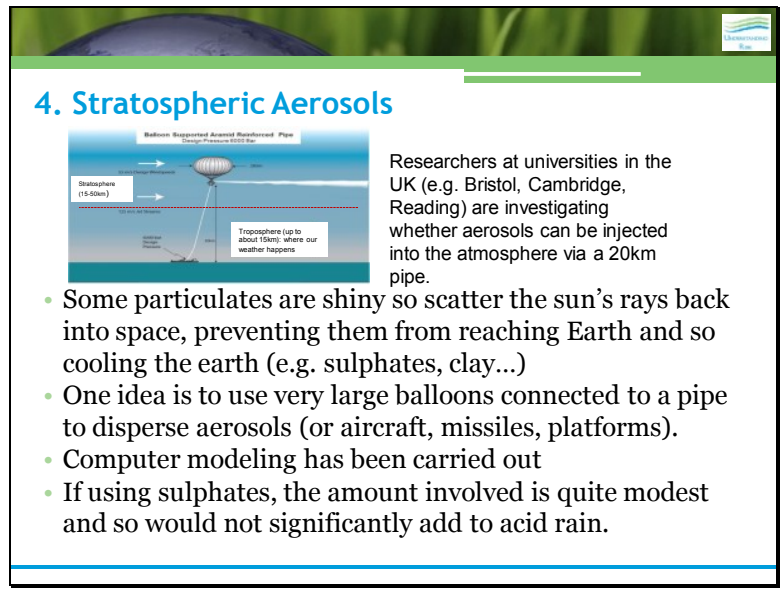

12

Sulphate particles pros \& cons
Pros
- Works fast could start lowering temperatures within a year
- Would reduce the global average temperature in a fairly uniform
way
Cons
If you suddenly stopped the world get warmer more quickly
- Effects would only last about 1-3 years so have to be repeated
Difficult to get the aerosol up that high and to release it
Very uncertain side effects may affect the climate/rainfall and
lead to droughts
Could damage the ozone layer and high altitude clouds
Other impacts of rising carbon emissions still remain e.g.
increasing ocean acidification

